\title{
Aspectos epidemiológicos do míldio da cebola na região do alto vale do Itajaí em Santa Catarina
}

\author{
Leandro Luiz Marcuzzo ${ }^{1}$, Jaqueline Carvalho ${ }^{1,2}$, Aline Nascimento ${ }^{1,3}$
}

${ }^{1}$ Instituto Federal Catarinense - IFC/Campus Rio do Sul, CP 441, CEP 89.163-356, Rio do Sul, SC. ${ }^{2}$ Bolsista Pibiti/CNPq, ejaquelinecarvalho1991@ gmail.com. ${ }^{3}$ Bolsista Pibic/CNPq, e-mail: aline.nine@outlook.com

Autor para correspondência: Leandro Luiz Marcuzzo (leandro.marcuzzo@ifc.edu.br)

Data de chegada: 15/03/2016. Aceito para publicação em: 18/04/2017.

$10.1590 / 0100-5405 / 2169$

\section{RESUMO}

Marcuzzo, L.L.; Carvalho, J.; Nascimento, A. Aspectos epidemiológicos do míldio da cebola na região do alto vale do Itajaí em Santa Catarina. Summa Phytopathologica, v.43, n.3, p.218-222, 2017.

Com objetivo de estudar a epidemiologia do míldio da cebola causada por Peronospora destructor na região do alto vale do Itajaí/SC, um ensaio foi conduzido com plantas naturalmente infectadas, nas safras $2014 \mathrm{e}$ 2015. A cada sete dias e, durante 19 semanas, foi quantificada a população de esporângios no ar, registrada as condições ambientais e avaliada a severidade nas plantas. Observou-se, que mesmo com ambiente favorável à doença, seu início ocorreu após nove semanas após o transplante das plantas. Constatou-se que a epidemia iniciou uma semana antes da primeira detecção do inóculo no ar. O progresso da doença foi representado pelo modelo de Gompertz y $=0,42636 *(\exp (-442,06555 * \exp (-0,50749 * x)))$. A produção foi de 34.930 e $15.773 \mathrm{Kg} \cdot \mathrm{ha}^{-1}$ de bulbos nos respectivos anos de avaliação. Este estudo epidemiológico pode fornecer informações do momento do início da epidemia e ser útil na validação de um sistema de previsão do míldio da cebola.

Palavras-chave: Allium cepa, epidemiologia, Peronospora destructor.

\section{ABSTRACT}

Marcuzzo, L.L.; Carvalho, J.; Nascimento, A. Epidemiological aspects of onion downy mildew in the region of Alto Vale do Itajaí, Santa Catarina State, Brazil.Summa Phytopathologica, v.43, n.3, p.218-222, 2017.

With the aim of studying the epidemiology of onion downy mildew caused by Peronospora destructor in the region of Alto Vale do Itajaí, Santa Catarina State, Brazil, an assay was conducted with naturally infected plants in 2014 and 2015 growing seasons. At every seven days, for 19 weeks, the population of sporangia in the air was quantified, the environmental conditions were recorded and the severity in plants was evaluated. Even in an environment favorable to the disease, its onset occurred at nine weeks after transplanting. Epidemics started one week before the first detection of inoculum in the air. The disease progress was represented by the Gompertz model $y=0.42636 *(\exp (-442.06555 * \exp (-0.50749 * x)))$. The yield was 34,930 and $15,773 \mathrm{Kg} \cdot \mathrm{ha}^{-1}$ bulbs in the respective years of evaluation. This epidemiological study can provide information about the beginning of epidemics and can be useful in the validation of a forecast system for onion downy mildew

Keywords: Allium cepa, epidemiology, Peronospora destructor.

A cultura da cebola (Allium cepa L.) ocupa o terceiro lugar entre as hortaliças de expressão econômica do Brasil e constitui atividade socioeconômica de relevante para pequenos produtores da região sul. $\mathrm{O}$ Estado de Santa Catarina possui a maior área de cultivo da cebola e, na safra de 2015, a produção atingiu 426.916 toneladas (12) representando $28 \%$ do total produzido do país sendo que $70 \%$ está concentrada na região do Alto Vale do Itajaí (3).

$\mathrm{Na}$ cultura da cebola, diversos são os fatores que contribuem para a baixa produtividade da cultura, e dentre estes, estão às doenças de diversas etiologias, que causam danos à cultura. Entre estas, o míldio causado por Peronospora destructor (Berk.) Casp. é uma doença de importância econômica na região do alto vale do Itajaí. $\mathrm{Na}$ época de cultivo ocorrem condições de temperaturas amenas (abaixo de $22^{\circ} \mathrm{C}$ ) e alta ( $\geq 90 \%$ ) umidade relativa do ar. A doença incide em toda a parte aérea da planta resultando na redução da produtividade (24).

No estudo de epidemias, a dinâmica temporal das doenças de plantas tem sido enfatizada, pois o progresso de doenças é frequentemente é facilmente visualizada (13). Para estabelecer relações entre o progresso de uma epidemia é necessário conhecer as condições ambientais favoráveis para o desenvolvimento do patógeno (22). Trabalhos envolvendo acompanhamento epidemiológico têm como objetivo constatar períodos da cultura em que ocorre maior intensidade da doença (2), onde o monitoramento da flutuação da população de esporos no ar também é utilizado para avaliar a dinâmica do progresso da doença $(20,21)$.

Para o caso do míldio da cebola, dentre os aspectos epidemiológicos, desconhece-se o comportamento da doença nas condições de campo quanto ao início e progresso de epidemia e, portanto, este trabalho pretendeu relacionar variáveis ambientais com a flutuação da população de esporângio no ar, a severidade da doença e a produtividade da cultura.

\section{MATERIAL E MÉTODOS}

O estudo epidemiológico do míldio da cebola foi conduzido no Instituto Federal Catarinense - IFC/Campus Rio do Sul, no município de Rio do Sul - SC, (Latitude: 27¹1'07' S e Longitude: 49³9'39', $\mathrm{W}$, altitude 655 metros acima do nível do mar) durante o período de 2 


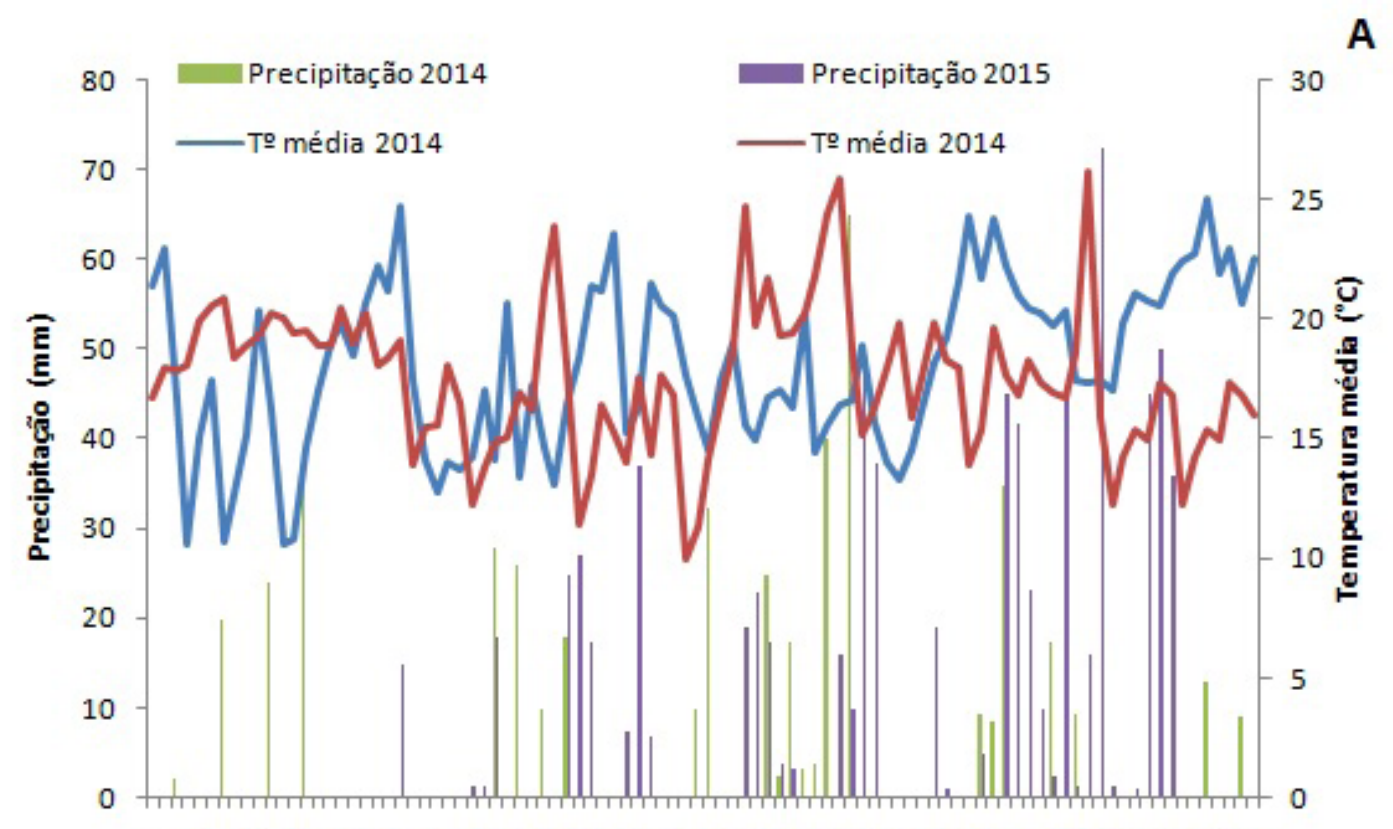

$159131721252933 \quad 374145495357616569737781858993$

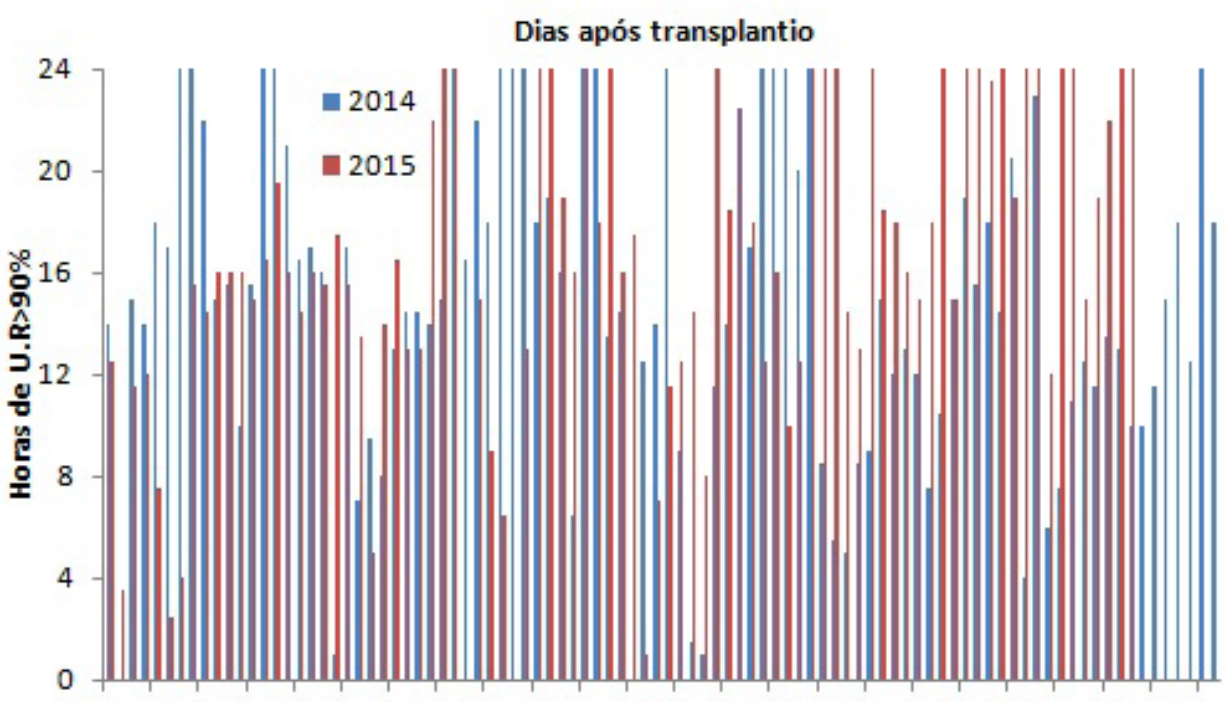

B

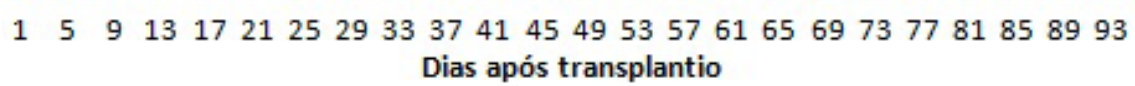

Figura 1. Flutuação da precipitação pluvial $(\mathrm{mm})$, da temperatura média do ar $\left({ }^{\circ} \mathrm{C}\right)(\mathrm{A})$ e da umidade relativa $\geq 90 \%$ (horas) (B) durante o período do estudo do míldio da cebola. IFC/Campus Rio do Sul 2014 e 2015.

de julho a 7 de novembro de 2014 e de 29 de junho a 30 de outubro de 2015 totalizando 19 semanas após o transplante das mudas.

O registro das variáveis meteorológicas como temperatura, umidade relativa e precipitação pluvial foram obtidos em uma estação meteorológica (Davis vantage vue ${ }^{\circledR}$ ) instalada no local do experimento.

Mudas sadias de cebola da cultivar Empasc 352, Bola Precoce, com 60 dias de idade foram transplantadas para o campo em parcelas com quatro repetições. Cada unidade experimental foi constituída por uma área de 1,65x2,00m, com cinco linhas espaçadas de $33 \mathrm{~cm}, 10 \mathrm{~cm}$ entre plantas, totalizando 100 plantas, equivalente a 300.000 planta.ha ${ }^{-1}$. Para avaliação do míldio e da produtividade 10 plantas em cada parcela foram previamente escolhidas e marcadas aleatoriamente na parcela. A calagem, adubação, tratos culturais seguiram as normas da cultura
(4). Não se utilizou inseticidas devido a não ocorrência de insetos no período de avaliação.

Em ambos os anos, ao redor do experimento foi transplantado a cada um metro linear uma muda de cebola contaminada naturalmente com míldio proveniente da EPAGRI/Estação experimental de Ituporanga (local com ocorrência natural da doença) para servir de fonte de inóculo da doença na área do experimento.

A coleta dos esporângios de $P$. destructor no ar foi feita utilizandose um coletor de esporos tipo "cata-vento" (20), posicionado a 0,4 metro acima do solo e localizado no centro do experimento. No coletor colocou-se uma lâmina de microscopia $(7,5 \times 2,5 \mathrm{~cm})$ untada com vaselina e substituída semanalmente. Em laboratório, a superfície da lâmina foi dividida em dois pontos centrais nos quais se adicionou 


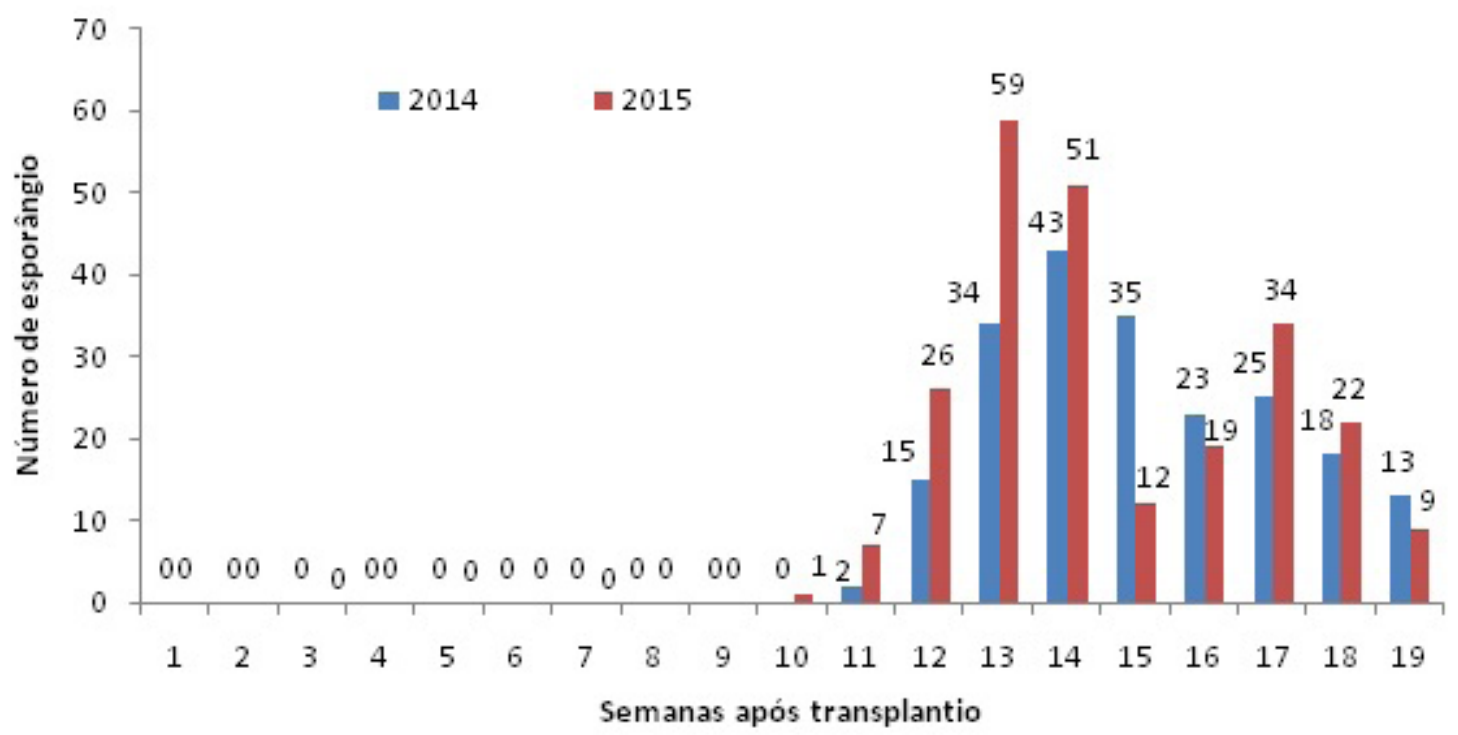

Figura 2. População de esporângios coletados semanalmente após o transplante da cebola. IFC/Campus Rio do Sul 2014 e 2015.

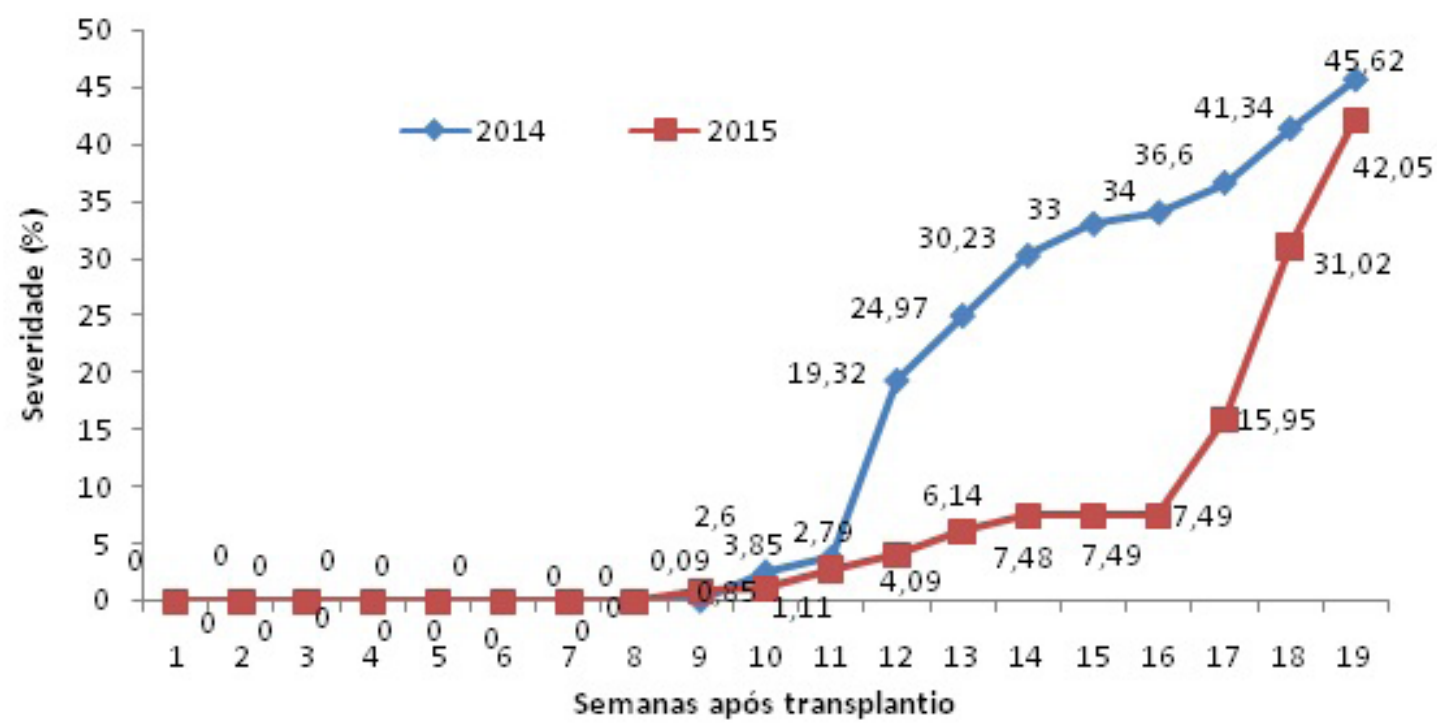

Figura 3. Severidade (\%) foliar observada do míldio da cebola (Peronospora destructor) em semanas após o transplante da cebola. IFC/Campus Rio do Sul 2014 e 2015.

duas gotas de azul de Amann e cobertas com uma lamínula de 1,8 x 1,8 $\mathrm{cm}\left(3,24 \mathrm{~cm}^{2}\right)$. Através da visualização em microscópio ótico, com a objetiva de 10 vezes, quantificou-se o número de esporângios coletados.

A severidade da doença foi estimada semanalmente através da porcentagem de área foliar afetada pela doença em cada folha exposta.

Nas dez plantas avaliadas para a intensidade da doença determinouse a produtividade de bulbos com diâmetro transversal acima de $35 \mathrm{~mm}$.

Modelos não lineares, comumente usados para representar crescimento de epidemias como o Logístico e o de Gompertz foram usados para ajuste com os dados observados. Os critérios estabelecidos para comparação dos modelos, em função da qualidade do ajustamento dos dados foram: a) erro padrão da estimativa; b) estabilidade dos parâmetros; c) erro padrão dos resíduos; d) visualização da distribuição dos resíduos ao longo do tempo e e) pseudo $\mathrm{R}^{2}$.

O progresso da doença foi relacionado à variação da população de esporângio no ar e comparada com as condições ambientais para a elaboração de uma fundamentação teórica da epidemiologia do míldio da cebola.

\section{RESULTADOS E DISCUSSÃO}

Para estabelecer as relações entre o progresso de uma doença e as condições ambientais é necessário conhecer os fatores ambientais favoráveis ao desenvolvimento da doença (22). Durante o período de avaliação constatou-se que ocorreu na safra de 2015 uma precipitação pluvial de $753,22 \mathrm{~mm}, 62 \%$ a mais do que em 2014, na qual foi registrado $464,7 \mathrm{~mm}$ (Figura 1A). Isso fez com que o progresso da doença em 2015 fosse afetado (Figura 3) e,conforme descrito por Hildebrand \& Sutton (10), não houve a esporulação na planta em 
decorrência da remoção dos esporângios pelo impacto das gotas da chuva. Em decorrência houve redução da infecção com reflexo no progresso, com pequeno incremento da $9^{\text {a }}$ a $16^{\text {a }}$ semanana safra 2015 (Figura 3). No entanto, apesar de altos índices pluviais que ocorreram nos últimos 30 dias em 2015, a doença teve um acentuado progresso a partir da $16^{\circ}$ semana, isso, provavelmente, porque os esporângios coletados anteriores (Figura 2) a esse período garantiram a infecção e, por isso, a chuva não influenciou o progresso da doença (Figura 3). Haveroth et al. (6) também não encontraram correlação significativa da precipitação pluvial com o aumento da intensidade da doença, indicando que, após a infecção, ela não interfere no progresso da doença.

A temperatura média do ar foi de $18^{\circ} \mathrm{C}$ e $17,7^{\circ} \mathrm{C}$ respectivamente em 2014 e 2015 no período de 19 semanas (Figura 1A), condição favorável ao desenvolvimento da doença (9). P. destructor tem diferentes requerimentos térmicos em cada fase do seu ciclo de vida. $\mathrm{Na}$ germinação dos esporângios a faixa ótima é de 10 a $12^{\circ} \mathrm{C}$, na formação do apressório de 10 a $22^{\circ} \mathrm{C}$ e na infecção de 6 a $22^{\circ} \mathrm{C}(7,8)$. Temperaturas semelhantes foram registradas no período de avaliação, sendo que a média das máximas foi de 22,25 e $21,22{ }^{\circ} \mathrm{C}$ e a média da mínima em 13,8 e $14,12^{\circ} \mathrm{C}$ e respectivamente em 2014 e 2015.

Constatou-se que o período de duração da umidade relativa do ar acima dos 90\%, foi de 14,86 e 16,22 horas para 2014 e 2015 respectivamente (Figura 1B). A presença de umidade relativa alta é fundamental para o ciclo de vida do patógeno conforme constatado por Hildebrand \& Sutton (11). No entanto Hildebrand \& Sutton $(8,9)$, verificaram discrepância entre autores, citando que os valores podem variar de 80 a $95 \%$ de umidade relativa. Leach et al. (16) verificaram que P.destructor necessita de umidade relativa do ar acima de $73 \%$ para haver liberação dos esporângios quando a temperatura for de $18^{\circ}$ C. Independentemente das condições ambientais de cada fase do ciclo de vida do patógeno, as condições de umidade relativa do ar foram satisfeitas em ambos os anos de avaliação. $O$ fato de ter encontrado altas horas de umidade relativa acima dos 90\% (Figura 1B) é característica da região, pois é em um vale próximo a serra geral e o que resulta na acumulação da umidade.

O início da doença a partir da $8^{\mathrm{a}}$ semana nas duas safras, pode ser explicado por alguns fatores, já que as condições ambientais ao patógeno foram favoráveis em todo o período. Um deles pode ter sido as folhas mais velhas que apresentam menor cerosidade, resultando em maior retenção do molhamento propiciado pela chuva o que favorece a infecção (10). Outro aspecto da severidade ter se acentuado à partir da $11^{\mathrm{a}}$ semana pode ser devido a maior translocação de carboidratos das folhas mais velhas para os bulbos (25). Nas folhas que estão iniciando processo de senescência, ocorre a liberação desses compostos internamente no tecido foliar (19), disponibilizando esses nutrientes e facilitando a colonização e reprodução do patógeno. $\mathrm{O}$ início da ocorrência da doença e a fenologia do hospedeiro também foi relacionada por Barratt \& Richards (1) no patossistema Alternaria solani (Ell.\& Martin) Jones \& Grout. e Xanthomonas spp por Marcuzzo et al. (17) na cultura do tomateiro.

Outro aspecto evidenciado foi que a doença teve início (Figura 3) uma semana antes da coleta de esporângios no ar (Figura 2). Hildebrand \& Sutton (10) também coletaram esporângios do míldio da cebola após ocorrer a esporulação em plantas doentes, similar ao encontrado com a ferrugem asiática da soja (14). À medida que aumenta a severidade da doença (Figura 3) ocorreu um incremento do número de esporângios na 13 e $14^{\mathrm{a}}$ semana em ambos os anos. Após a $14^{\mathrm{a}}$ semana do início da doença em ambos os anos, observou-se um decréscimo gradual dos esporângios coletados principalmente em 2015, o que pode ser atribuído precipitação pluvial que ocorreu nas quatro últimas semanas (Figura 1A). O menor número de esporângios coletados ocorreu na última semana antes da colheita dos bulbos, isso pode ser associado ao fato de que as folhas já se encontravam em senescência (Figura 2). Keske (15) avaliando a flutuação de esporos de Monilinia fructicola (Wint) Honey, agente causal da podridão parda do pessegueiro, coletados em armadilhas do tipo "cata-vento", observou que foi constante a coleta durante o período vegetativo da cultura e não apenas na colheita que teve uma alta incidência da doença. Isso evidência que o inóculo presente no ambiente serve de um indicativo para a ocorrência da doença, como ocorre em sistema de plantio direto do milho (20). Esse mesmo fato foi verificado por Duffeck \& Marcuzzo (18) em quantificação dos esporângio de $P$. destructor no ar, num período de três anos, evidenciando uma relação significativa entre a presença dos esporângios no ar com o progresso da doença.

Durante o período de bulbificação ocorreu a maior severidade da doença, entre a $11^{\mathrm{a}}$ e $16^{\mathrm{a}}$ semanas respectivamente em 2014 e 2015 . Em 2015 esse período de bulfificação foi mais curto, crescendo de 7,49\% para $42,05 \%$ em três semanas, enquanto que em 2014 a severidade aumentou de $19,32 \%$ para $45,62 \%$ num período de oito semanas (Figura 3). A severidade final de $29,25 \%$ foi relatada por Wordell Filho et al. (23). A epidemia foi melhor ajustada pelo modelo de Gompertz na safra de 2014, sendo descrita pela função y $=0,42636^{*}\left(\exp \left(-442,06555^{*} \exp (-\right.\right.$ $0,50749 * x))),\left(R^{2}=0,99865\right)$, onde a taxa $(0,50749)$ nas condições observadas, comprova o avanço da doençaapós a $11^{\mathrm{a}}$ e $16^{\mathrm{a}}$ semana em 2014 e 2015 respectivamente (Figura 2). Haveroth et al. (5) avaliando uma epidemia de míldio em 2011 verificaram uma taxa de 0,55, similar ao encontrado no presente trabalho.

A produtividade de bulbos comerciais foi de 34.930 e 15.773 Kg.ha-1 respectivamente nas safras de 2014 e 2015, valores esses intermediários aos $28.040 \mathrm{Kg} \cdot \mathrm{ha}^{-1}$ encontrados por Wordell Filho et al. (23). A diferença de $54,84 \%$ em 2015 provavelmente se deve a um menor número de dias com luminosidade, já que em grande parte dos dias houve chuvas (Figura 1) e/ou foram nublados, além da lixiviação dos nutrientes do solo pelo excesso hídrico.

Este estudo exploratório de alguns aspectos da epidemiologia contribuiu para estabelecer o momento do início e do progresso da doença com as condições ambientais, fatores que poderão ser úteis na validação de um sistema de previsão para míldio da cebola.

\section{AGRADECIMENTOS}

Os autores agradecem o apoio financeiro recebido do Conselho Nacional de Desenvolvimento Científico e Tecnológico - CNPq - Brasil no projeto "Validação de um sistema de previsão do míldio Peronospora destructor da cebola" processo: 470176/2013-0.

\section{REFERÊNCIAS}

1. Barratt, R.W.; Richards, M.C. Physiological maturity in relation to Alternaria blight in the tomato. Phytopathology, St. Paul, v.34, n.12, p.997, 1944. (Abstract).

2. Bergamim Filho, A.; Amorim, L. Doenças de plantas tropicais: epidemiologia e controle econômico. São Paulo: Ceres, 1996. 299 p.

3. Boeing, G. Fatores que afetam a qualidade da cebola na agricultura familiar Catarinense. Florianópolis: Instituto CEPA, 2009. 88p.

4. Epagri. Sistema de produção para a cebola: Santa Catarina. Florianópolis: Epagri, 4a revisão, 2013. 106p. (Epagri. Sistema de produção 46).

5. Haveroth, R.; Marcuzzo, L.L.; Duffeck, M.R.; Nunes, R.C.T. Progresso temporal do míldio da cebola (Peronospora destructor) na região do alto 
vale do Itajaí/SC. Summa Phytopathologica, Botucatu, v.38, supl., 2012. (1 CD-ROM)

6. Haveroth, R.; Nunes, R.C.T.; Duffeck, M.R.; Marcuzzo, L.L.; Neves, L.O. Relação da precipitação pluvial sobre a severidade do míldio (Peronospora destructor) da cebola. In: XVII Congresso Brasileiro de Meteorologia, Gramado. Anais. Gramado: SBMet, 2012. 1 CD-ROM.

7. Hildebrand, P.D.; Sutton, J.C. Effects of weather variables on spores survival and infection of onion leaves by Peronospora destructor. Canadian journal plant pathology, Ottawa, v.6, p.119-126, 1984.

8. Hildebrand, P.D.; Sutton, J.C. Interactive effects of the dark period, humid period, temperature, and light on sporulation of Peronospora destructor. Phytopatology, St. Paul, v.74, n.12, p.1444-1449, 1984.

9. Hildebrand, P.D.; Sutton, J.C. Relationships of temperature, moisture, and inoculum density to the infection cycle of Peronospora destructor. Canadian journal plant pathology, Ottawa, v.6, p.127-134, 1984.

10. Hildebrand, P.D.; Sutton, J.C. Weather variables in relation to epidemic of downy mildew. Phytopathology, St. Paul, v.72, n.3, p.219-224, 1982.

11. Hildebrand, P.D.; Sutton, J.C. Maintenance of Peronospora destructor in onion sets. Canadian journal plant pathology, Ottawa, v.2, n.4, p.239240, 1980.

12. IBGE. Estatística da produção agrícola, março de 2015. Brasília/DF, 2015 Disponível em: $<$ http://ftp.ibge.gov.br/Producao_Agricola/fasciculo_Indicadores_IBGE/estProdAgr_201503.pdf.>.Acessoem: 02 fev. 2016.

13. Jeger, M.J. Analysing epidemics in time and space. Plant Pathology, Oxford, v.32, n.1, p.5-11, 1983.

14. Juliatti, F.C.; Rezende, A.A.; Vale, F.X.R. Critérios práticos de fundamento epidemiológico que auxiliam na tomada de decisão para o controle de doenças de plantas. Tropical PlantPathology, Brasília, DF, v.35, p.23-25, 2010. Suplemento.

15. Keske, C. Epidemiologia da podridão parda em pessegueiros conduzidos em sistema de produção orgânico no alto vale do Itajaí - SC. 2009. 119f. Tese (Doutorado em Produção Vegetal) - Universidade Federal do Paraná, Curitiba.
16. Leach, C.M.; Hildebrand, P.D.; Sutton, J.C. Sporangium discharge by Peronospora destructor: influence of humidity, red-infrared radiation and vibration. Phytopathology, St. Paul, v.72, n.8, p.1052-1056, 1982.

17. Marcuzzo, L.L.; Becker, W.F.; Fernandes, J.M.C. Alguns aspectos epidep miológicos da mancha bacteriana (Xanthomonas spp.) do tomateiro na região de Caçador/SC. Summa Phytopathologica, Botucatu, v.35, n.2, p.132-135, 2009.

18. Marcuzzo, L.L.; Duffeck, M.R. Flutuação populacional de esporângios de Peronospora destructor no ar e sua relação com severidade do míldio da cebola. Summa Phytopathologica,Botucatu,v.41, n.1, p.68-70, 2015.

19. Pereira-Netto, A.D. Crescimento e desenvolvimento. In: Wachowick, C.M.; Carvalho, R.I.I. (Org.). Fisiologia vegetal: produção e pós-colheita. Curitiba: Champagnat, cap.1, p.17-41, 2002.

20. Reis, E.M.; Mário, J.L. Quantificação do inóculo de Diplodia macrospora e de $D$. maydis em restos culturais, no ar, e sua relação com a infecção em grãos de milho. Fitopatologia Brasileira, Brasília, DF, v.28, n.2, p.143147, 2003

21. Reis, E.M.; Santos, H.P. População de Helmintosporium sativum no ar quantificado através de uma armadilha tipo cata-vento. Fitopatologia Brasileira, Brasília, DF, v.10, n.5, p.515-519. 1985.

22. Vale, F.X.R.; Zambolim, L. Influência da temperatura e da umidade nas epidemias de doenças de plantas. Revisão Anual de Patologia de Plantas, Passo Fundo, v.4, p.149-207, 1996.

23. Wordell Filho, J. A.; Martins, D.A.; Stadnick, M.J. Aplicação foliar de tratamentos para controle do míldio e da podridão-de-escamas em bulbos de cebola. Horticultura brasileira, Brasília, v.25, n.4, p.544-549, 2007.

24. Wordell Filho, J. A.; Boff, P. Míldio. In: Wordell Filho, J.A.; Rowe, E.; Gonçalves, P.A.; Debarba, J.F.; Boff, P.; Thomazelli, L.F.. Manejo Fitossanitário na cultura da cebola. Florianópolis: EPAGRI, p.31-43, 2006.

25. Zuffelato-Ribas, K.C. Ecofisiologia. In: Wachowick, C.M.; Carvalho, R.I.I. (Org.). Fisiologia vegetal: produção e pós-colheita. Curitiba: Champagnat, cap.2, p.43-61. 2002. 